\title{
Ensino, pesquisa e práxis na formação docente
}

\author{
Teaching, research and praxis in teacher formation
}

Docencia, investigación y práctica en la formación del

profesorado

MARIA JUCILENE LIMA FERREIRA (iDa

\section{Resumo}

$\mathrm{O}$ ato de ensinar requer, sobremaneira, o estudo aprofundado daquilo que se ensina e a definição clara dos fins da ação pedagógica. Este artigo investiga as relações entre ensino, pesquisa e práxis estabelecidas no processo de formação inicial de docentes em serviço e no processo de produção do conhecimento desses profissionais e indagar sobre essa proposta de ensino e suas contribuições na formação docente. Trata-se mais especificamente da experiência com os componentes curriculares Fundamentos da Práxis VI e Estágio Supervisionado VI, no curso de Pedagogia do Programa Nacional de Formação de Professores da Educação Básica (PARFOR), da Universidade do Estado da Bahia (UNEB). O estudo visa, sobretudo, investigar as relações entre ensino, pesquisa e práxis estabelecidas no processo de formação inicial de docentes em serviço e no processo de produção do conhecimento dos profissionais, vinculados à Rede Municipal de Medeiros Neto - BA, no $6^{\circ}$ semestre do curso de Pedagogia, em uma turma de 20 (vinte) graduandos. A pesquisa se apoia no materialismo histórico dialético, adota a tendência pesquisa/participante/ação e se utiliza da revisão de literatura e pesquisa documental no processo de investigação. Os resultados apontam aspectos das relações entre ensino, pesquisa e práxis e das contribuições que tais aspectos oportunizam à docência.

Palavras-chave: Ensino. Pesquisa. Formação Docente.

\footnotetext{
a Universidade do Estado da Bahia (UNEB), Salvador, BA, Brasil. Doutora em Educação, email: juci.ferreira@bol.com.br
} 


\begin{abstract}
The act of teaching requires, above all, a thorough study of what is taught and a clear definition of the intentionality of the pedagogical action. This article, aims to investigate the relationships between teaching, research and praxis, established in the process of initial training of teachers in service and in the process of producing the knowledge of professionals. Hence, this study focuses on relationships between teaching, research and praxis in teacher education processes. It is more specifically the experience with the curricular components Fundamentals of Praxis VI and Supervised Internship VI, in the Pedagogy course of the National Basic Education Teachers Training Program (PARFOR), from the Universidade do Estado da Bahia (UNEB). The study aims, above all, to investigate the relationships between teaching, research and praxis, established in the process of initial training of teachers in service and in the process of producing the knowledge of professionals, linked to the Municipal Network of Medeiros Neto-BA, in the 6th semester of the course of Pedagogy, in a class of 20 (twenty) undergraduates. The research is supported by dialectical historical materialism, adopts the research/participant/action trend and uses literature review and documentary research in the investigation process. The results point out aspects of the relationships between teaching, research and praxis and the contributions that these aspects provide to teaching.
\end{abstract}

Keywords: Teaching. Research. Teacher Formation.

\title{
Resumen
}

El acto de enseñar requiere, sobre todo, un estudio exhaustivo de lo que se enseña y una definición clara de la intencionalidad de la acción pedagógica. Por lo tanto, este estudio se centra en las relaciones entre la enseñanza, la investigación y la praxis en los procesos de formación docente. Es más específicamente la experiencia con los componentes curriculares Fundamentals de la Praxis VI y Pasantía Supervisada VI, en el curso de Pedagogía del Programa Nacional del Formación de Docentes de la Educación Básica (PARFOR), de la Universidad Estatal de Bahía (UNEB). El estudio tiene como objetivo, sobre todo, investigar las relaciones entre la enseñanza, la investigación y la praxis, establecidas en el proceso de formación inicial de docentes en servicio y en el proceso de producción del conocimiento de los profesionales, vinculados a la Red Municipal de Medeiros Neto-BA, en el sexto semestre del curso. de Pedagogía, en una clase de 20 (veinte) estudiantes universitarios. La investigación está respaldada por el materialismo histórico dialéctico, adopta la tendencia de investigación / participante / acción y utiliza la revisión de la literatura y la investigación documental en el proceso de investigación. Los resultados apuntan aspectos de la relación entre la enseñanza, la investigación y la praxis y las contribuciones que estos aspectos proporcionan a la enseñanza y a los procesos de formación del profesorado para trabajar en la educación básica.

Palabras clave: Docencia. Investigación. Formación del Profesorado. 


\section{Introdução}

...Que linda camarinha! Era tão feia! - Você me disse um dia que sua vida era toda escuridão cinzenta, fria, sem um luar, sem um clarão... Por que você não experimenta? A moça foi tão bem sucedida...

Este artigo propõe uma análise sobre as relações entre ensino, pesquisa e práxis a partir do trabalho e da produção de conhecimento acerca da formação docente especificamente na experiência com os componentes curriculares Fundamentos da Práxis Pedagógica VI e Estágio Supervisionado VI, do curso de Pedagogia no âmbito do Programa Nacional de Formação de Professores da Educação Básica (PARFOR), da Universidade do Estado da Bahia (UNEB). Adiante, pretende-se expressar a lição que a metáfora da telha de vidro, no poema de Rachel de Queiroz, supracitado, anuncia para processos de formação docente. Ao se refletir sobre uma telha de vidro nos percursos da profissão docente, ela é relacionada à linha de pensamento e ação que conduziu o trilhar de caminhos da formação para a profissão docente.

As atividades docentes e as relações que se estabelecem com o outro nas interações pedagógicas requerem atenção profunda, observação sistemática e rigorosa daquilo que se faz no âmbito da profissão docente e da realidade social envolvida a telha de vidro pode ser considerada, em analogia, essa observação sistemática e rigorosa da realidade e do fazer profissional?

A partir dessas reflexões, considera-se que os processos formativos, no âmbito da educação superior e da educação básica, podem contribuir de modo mais efetivo com a produção do conhecimento crítico e de perspectiva emancipatória, na medida em que estes se dão como prática social, na inter-relação com o outro pesquisando, mediante análise, reflexão, prática e produção de conhecimento novo. Para que tal ideia não seja interpretada como romântica ou panfletária, ressalta-se que esse processo formativo não se dá num toque de mágica ou sob responsabilidade apenas do docente, uma vez que 
exige condições materiais próprias para que o trabalho pedagógico dessa natureza possa ser desenvolvido no cotidiano da vida acadêmica e da escola.

Assim, abordam-se, a seguir, o conceito de ensino, a função social de ensinar, o lugar da docência e a indissociabilidade entre teoria-prática, trazendo-se à tona algumas produções acadêmicas para a docência.

\section{O ensino: relações entre docente e discente e a indissociabilidade teoria-prática (práxis)}

Toma-se como princípio o pensamento freireano de que "ensinar não é transmitir conhecimento" (FREIRE, 2005, p. 47). Essa assertiva faz o anúncio do ato de ensinar como construção coletiva de conhecimento, pela comunicação que ele requer. E essa comunicação expressa uma relação horizontal, e não verticalizada, que se estabelece com o outro em situação de aprendizagem. Contudo, isso não significa dizer que não haja definições de papéis e respectivas especificidades. Pelo contrário, essa relação horizontal permite interações e mediações que tanto o docente quanto o discente realizam à medida que atuam como sujeitos do processo de ensino-aprendizagem.

Nesse sentido, a relação entre docente e discente ancora-se no pressuposto de que quem ensina também aprende, e vice-versa. Os seres humanos são seres históricos e, como tais, são produtores de cultura, determinados, mas também determinantes dos valores criados pelo ser humano em cada tempo e lugar. Trata-se do processo de ensino-aprendizagem em que se explicita a definição clara, para ambas as partes (docente e discente), dos objetivos que estão postos para a produção do conhecimento, de modo que seja possível garantir diálogo, comunicação, engajamento e cumplicidade acerca do conteúdo do trabalho pedagógico que é feito.

Não se pensa o ensino desconectado de um contexto. A consideração do ensino como uma prática educacional, historicamente situada, impõe à Didática a necessidade de compreender seu funcionamento e suas implicações estruturais, buscando ao mesmo tempo olhar para si mesma. [...] Tratar o fenômeno do ensino como uma totalidade concreta, buscar suas determinações, pensá-lo em conexão com outras práticas sociais, é o que se procura fazer, do ponto de vista de uma concepção crítica do trabalho da Didática (RIOS, 2010, p. 55). 
Essa forma de pensar os pressupostos teórico-metodológicos do ensino tem um desdobramento ainda maior quando se recorre à ética da docência, ou seja, aquela docência preocupada e atenta ao processo de conhecimento e que se dê articulada ao reconhecimento do outro e com respeito ao outro. A dimensão ética da atividade docente subsidia as relações entre docente e discente, ao mesmo tempo em que colabora para a definição de objetivos, a seleção de conteúdo/forma e a avaliação dos processos de ensino-aprendizagem.

Etimologicamente, o termo docência significa ação de ensinar (FREIRE, 2005; VEIGA; ARAÚJO; KAPUZINIAK, 2005; ROLDÃO, 2007; RIOS, 2010; FERREIRA, 2015). Todavia, a docência não se restringe apenas ao ensino; é o trabalho do professor, no qual os profissionais desempenham um conjunto de funções para além da tarefa de ministrar aulas. Portanto, inclui o ensino, mas não se atém exclusivamente a ele, conforme consta na Lei de Diretrizes e Bases da Educação Nacional — LDBEN (Lei n. ${ }^{\circ}$ 9.394/1996), em seu artigo $13^{\circ}$ (BRASIL, 1996).

Há, nesse dispositivo da LDBEN, uma considerável ampliação das atividades da docência, na medida em que esta se estende a outras funções, que incluem elaboração de projetos e articulação entre escola e comunidade. Neste ponto, cabe ressaltar o seguinte conceito de docência:

A docência para si é portadora de duas dimensões indissociáveis: uma individual e outra coletiva. A primeira diz respeito à particularidade do profissional, da articulação do seu pensamento e da sua prática. Nela reside sua peculiaridade, sua singularidade intelectual. Já a segunda diz respeito à natureza social da docência, não só porque ela se dá na relação com outrem, ou seja, na sua relação com o educando e com as condições sociais disponíveis, mas também porque o conteúdo dessa relação está, pela própria natureza, articulado no contexto sociocultural e político em que o professor e os educandos estão inseridos. (FERREIRA, 2015, p. 79).

A docência, ao ser compreendida com a abrangência que a legislação lhe confere e ao corresponder às duas dimensões supracitadas, exige ampliação do trabalho docente e, ao mesmo tempo, significa que é um trabalho que se realiza por larga característica coletiva.

Ora, se no ato de ensinar ensina-se alguma coisa a alguém, essa constatação por si só já expressa a negatividade de ação isolada, unitária, unilateral. Ademais, a sala de aula é composta pelo docente e pelos discentes, por conseguinte não pode ser 
verticalmente compreendida como propriedade docente, mas, sim, como espaço coletivo dos processos de ensino e aprendizagem.

Ensinar pressupõe produzir conhecimento sistematizado, rigoroso, de caráter acadêmico-científico. Esse conhecimento, tal como defendido aqui, é condição sine qua non para a docência comprometida com processos formativos de perspectiva críticoemancipadora, por um processo de comunhão — a produção de conhecimento a partir do trabalho coletivo, das relações de reciprocidade, de coletividade e, até mesmo, de solidariedade intelectual — como preconizado por Freire (2005).

Contudo, vale ressaltar que o trabalho coletivo entre docente, discente e os respectivos pares é atividade criadora rica em consensos, mas também em conflitos e contradições. Dialeticamente, reúne avanços e retrocessos das tarefas definidas em conjunto, porque abarca aproximações e diferenças no processo de sua realização.

Por trabalho coletivo entendemos aquele que se desenvolve integralmente, com a participação efetiva dos sujeitos envolvidos em uma dada atividade, munidos de uma intencionalidade e objetivos comuns. Em vez de ser uma divisão de tarefas para um grupo de pessoas resolver um problema ou mesmo atingir um determinado fim, são atividades que envolvem pessoas cientes da finalidade do próprio trabalho e do seu conjunto, da importância desse trabalho e de suas etapas. Essas pessoas se dispõem a avaliar, continuadamente, o andamento do trabalho individual e coletivo, bem como seus respectivos resultados (FERREIRA; MOLINA, 2016, p. 115).

Por conseguinte, a intencionalidade do trabalho pedagógico e da docência, propriamente dita, se faz também elementar, na medida em que pressupõe a clareza dos fins dos processos formativos e dos subsídios teórico-metodológicos relacionados a dada concepção de formação. "Ninguém pode estar no mundo, com o mundo e com os outros de forma neutra. Não posso estar no mundo de luvas nas mãos constatando apenas" (FREIRE, 2005, p. 77, grifo do autor). Sobretudo no âmbito da formação docente e das relações entre docente e discente, a dimensão política requer ainda maior concretude.

Este trabalho parte da compreensão de que o trabalho pedagógico, bem como sua opção por princípios coletivos, tem um papel político que lhe é imanente, portanto, a forma como é definido, caracterizado e conduzido responde a uma proposta política de educação e de sociedade. Estar ciente desse papel político pode contribuir para a materialidade do Projeto Histórico da classe trabalhadora, entendido 
como "a delimitação do tipo de sociedade que se quer criar (já que todos defendemos a 'transformação social') e as formas de luta para a concretização dessa concepção, a partir das condições presentes" (FREITAS, 1987, p. 122).

A docência e o trabalho pedagógico como um todo, na formação de professores, pode ser uma das formas de luta para somar forças aos processos históricos de levar adiante a construção da sociedade sob uma outra lógica, que não aquela sob a égide do capital. Embora seja preciso considerar que as condições materiais determinam os processos de consciência dos sujeitos acerca da realidade em que estão inseridos, o pensar e o agir, pela práxis e pela intencionalidade pedagógica inerente à classe trabalhadora, tendem a contribuir como processos educativos críticos, de perspectiva emancipadora, revolucionários.

Conforme Marx e Engels (2009, p. 32), “são os homens que desenvolvem a sua produção material e o seu intercâmbio material que, ao mudarem essa sua realidade, mudam também o seu pensamento e os produtos do seu pensamento". Por isso mesmo, a produção e o intercâmbio que se estabelecem nas relações entre docente e discente ${ }^{1}$ são cruciais para definir o caráter dos processos formativos em questão. Daí se faz imprescindível a intencionalidade do trabalho pedagógico que se realiza nesses processos.

O "Projeto Histórico" embasa toda teoria educacional ou pedagógica dos projetos educacionais e deve nortear toda ação, entre elas e a atividade de pesquisa, no âmbito da educação. Este é o primeiro passo para elaboração de uma teoria revolucionária, orientadora da ação educativa daqueles que pretendam se tornar agentes efetivos da prática histórica (TAFFAREL, 2016, p. 19).

Nesse sentido, o Projeto Histórico é uma prerrogativa necessária à orientação da docência que se fundamenta na articulação entre teoria e prática (práxis), de modo que esse movimento de consistência teórica e sua âncora prática não podem prescindir da pesquisa e da produção do conhecimento a favor da vida, do amplo sentido da

\footnotetext{
${ }^{1}$ Aqui o entendimento é que, mesmo o produto do trabalho intelectual sendo considerado imaterial, não deixa de ser uma forma de produção, também explorada e largamente subsumida aos ditames do capital. Assim, "[...] trabalho material e imaterial, na imbricação crescente que existe entre ambos, encontram-se, entretanto, centralmente subordinados à lógica da produção de mercadorias e de capital. No universo da expansão da atividade intelectual dentro da produção" (ANTUNES, 2009, p. 128).
} 
saúde, da leitura crítica da realidade, tendo em vista a ampliação da consciência acerca desse Projeto Histórico.

No Brasil, os trabalhadores e as trabalhadoras do campo, junto aos movimentos sociais e sindicais populares do campo, têm protagonizado uma proposta de educação que caminha na direção de contribuir com o Projeto Histórico da classe trabalhadora. O Projeto de Educação do Campo, de perspectiva contra-hegemônica, protagonizado pelos sujeitos do campo organizados, visa, sobretudo, fortalecer a luta social dos povos do campo, contribuir com a compreensão crítica da realidade, tratar de questões inerentes ao trabalho no campo, ao modelo de produção agrícola hegemônico, à soberania alimentar, à cultura e à política pública de educação e de formação humana (MOLINA, 2010; CALDART, 2012a; FERREIRA, 2015).

As contradições próprias do modo de produção capitalista e da organização social podem funcionar também como possibilidade efetiva para a docência e para o trabalho pedagógico crítico-emancipador (CALDART, 2012b). No âmbito da docência, as contradições podem ser elementos concretos de indagação, de indignação e de observação, por processo de pesquisa que informe sobre conflitos, tensões e incoerências oriundas das propostas, ações sustentadas pelo capital.

Diante dessa expectativa, não cabe à docência estagnar-se na rotina diária dos afazeres, limitada a lamuriar as várias situações, contradições, condições materiais de trabalho, dificuldades e desafios que se apresentem à docência e ao trabalho pedagógico em geral, mas enfrentar, lutar, resistir coletivamente junto aos pares e a outras instâncias de ensino e da organização sindical, em nível local, nacional e internacional, buscando fortalecimento e engajamento político em prol da ampliação da profissionalidade docente e do reconhecimento e da valorização do magistério como profissão - a telha de vidro na profissão também pode contribuir com essa atividade.

\section{O caminho metodológico}

O materialismo histórico dialético constitui âncora para a interpretação do trabalho pedagógico realizado nos processos de formação dos docentes, a partir das categorias do trabalho, da práxis e das relações sócio-históricas das questões levantadas. Para isto, 
[...] deve ter presente em seu estudo uma concepção dialética da realidade natural e social e do pensamento, a materialidade dos fenômenos e que estes são possíveis de conhecer (TRIVIÑOS, 1987, p. 73).

Daí que coadunamos com o pensamento de Silva (2008) quando apresenta o conceito de pesquisa participante/ação, justificando a adoção dessa tendência de pesquisa pela relação de unidade que se estabelece entre teoria e prática e, por conseguinte, pela relação indissociável entre sujeito-objeto. Isso significa uma tendência investigativa que possibilita a interpretação da realidade a partir das contradições existentes na luta de classes e dos processos históricos da humanidade, com vistas à transformação das estruturas sociais hegemônicas. Participação-ação, no processo de pesquisa, se unem para caracterizar processos de estudo dentro da própria realidade em que o pesquisador se encontra inserido, mas o fato de estar inserido lhe é peculiar porque se propõe a inquietar-se, a problematizar, a estudar fenômenos e relações dessa mesma realidade.

Assim sendo, este estudo investiga as relações entre ensino, pesquisa e práxis estabelecidas no processo de formação inicial de docentes em serviço e no processo de produção do conhecimento dos profissionais vinculados ao $6^{\circ}$ semestre de Pedagogia, em uma turma de vinte graduandos.

O citado curso de Pedagogia é ofertado pela Universidade do Estado da Bahia (UNEB) em parceria com o Programa Nacional de Formação de Professores da Educação Básica (PARFOR). Segundo o projeto pedagógico do curso, o referido programa é destinado aos professores em exercício nas escolas públicas estaduais e municipais sem formação adequada aos requisitos dispostos na LDBEN. O PARFOR oferece cursos superiores públicos, gratuitos e de qualidade para os municípios de vinte e um estados da Federação, por meio de setenta e seis instituições públicas de educação superior, das quais quarenta e oito são federais e vinte e oito são estaduais, com a colaboração de quatorze universidades comunitárias (UNEB, 2008).

Para a realização deste estudo, buscou-se responder à seguinte indagação fundamental: Em que medida ensino e pesquisa articulados puderam contribuir com uma perspectiva crítica, coletiva e transformadora (práxis) na formação inicial de professores em um dos cursos de Pedagogia do PARFOR na UNEB, no ano de 2015? 
Com isso, o objetivo é analisar as relações entre ensino, pesquisa e práxis no trabalho pedagógico dos componentes curriculares Fundamentos da Práxis Pedagógica VI e Estágio Supervisionado VI do referido curso de Pedagogia, bem como as contribuições dessas relações para a formação docente.

Para tanto, lança-se mão de uma revisão de literatura, dos conceitos que subsidiaram todo o trabalho científico e de documentos oficiais como planejamentos, projetos e relatórios do curso, disponibilizados pela secretaria acadêmica do referido curso. Lança-se, ainda, ao desafio da realização do exercício investigativo sobre o próprio trabalho pedagógico, adotando a pesquisa participante ação como tendência investigativa para a produção de análise crítica sobre proposições formativas articuladas a inter-relação entre ensino, pesquisa e práxis na formação da docência.

$\mathrm{Na}$ seção a seguir, apresentam-se os resultados e discussões da pesquisa.

\section{Ensino, Pesquisa e Práxis: contribuições do Estágio em Pedagogia}

O estágio curricular supervisionado obrigatório nos cursos de Licenciatura Plena em Pedagogia é regulamentado pela Resolução do Conselho Nacional de Educação (CNE/CP) n 2, de 19 de fevereiro de 2002 (BRASIL, 2002), e pelas Diretrizes Curriculares Nacionais para o Curso de Graduação em Pedagogia, licenciatura, estabelecidas na Resolução CNE/CP no 1, de 19 de maio de 2006. Segundo o inciso IV do art. $8^{\circ}$ dessas diretrizes, o estágio curricular deve ser realizado, ao longo do curso, "de modo a assegurar aos graduandos experiência de exercício profissional, em ambientes escolares e não escolares que ampliem e fortaleçam atitudes éticas, conhecimentos e competências [...]" (BRASIL, 2006, p. 6), para atuação no campo profissional da Educação Infantil e nos anos iniciais do Ensino Fundamental (preferencialmente) e em outras áreas como nas disciplinas pedagógicas dos cursos de Ensino Médio, na modalidade normal, na Educação Profissional na área de serviços e de apoio escolar, na Educação de Jovens e Adultos, na participação em atividades da gestão de processos educativos, no planejamento, na implementação, na coordenação, no acompanhamento e na avaliação de atividades e projetos educativos, assim como em reuniões de formação pedagógica. 
Os textos de regulamentação supracitados enfatizam o estágio supervisionado como o lugar de exercício da experiência profissional - o que, de fato, ele é. No entanto, o trabalho de formação docente realizado no âmbito desse componente não pode restringir-se à especificidade técnica que lhe é atribuída, pois, na medida em que se considera a especificidade da docência, tal como aqui referida anteriormente, identificada como prática social e intencionalmente articulada ao Projeto Histórico da classe trabalhadora, esse lugar de experiência profissional se potencializa como possibilidade de produção de conhecimento e práxis.

Nesse sentido, “considerar o estágio como campo de conhecimento significa atribuir-lhe um estatuto epistemológico que supere sua tradicional redução à atividade prática instrumental” (PIMENTA; LIMA, 2004, p. 29). Ao longo do trabalho docente realizado pela autora deste texto, houve uma preocupação constante em fazer do estágio mais um espaço-tempo de produção de conhecimento, para a docente e para os graduandos, acerca dos processos formativos e de problemáticas da escola. Por essa perspectiva de condução do componente curricular estágio, não se pode perder de vista a pesquisa, na sua relação com o ensino, pois ela:

Está relacionada à criação de um corpo de conhecimentos sobre certo assunto, com características específicas; não se busca qualquer conhecimento, mas um conhecimento que ultrapasse a imediaticidade e aparência da realidade (SILVA, 2011, p. 28).

Dessa maneira, a pesquisa como atividade de rigor científico, metodologicamente estruturada e definida epistemologicamente por fundamentos teórico-metodológicos da investigação científica possibilita a realização de um trabalho pedagógico que problematize as inquietações e os desafios que se apresentam aos processos de ensino e de aprendizagem, de modo a encontrar luz/conhecimento aprofundado sobre o objeto de interesse do docente, da escola e/ou acerca das problemáticas do dia a dia da docência. Não obstante, haja vista a realidade mais ampla que envolve os fenômenos educativos, porque históricos, políticos e sociais, estes não podem ser interpretados apenas pela dimensão da realidade concreta aparente, pois, "se a aparência fenomênica e a essência das coisas coincidissem diretamente, a ciência e a filosofia seriam inúteis" (KOSIK, 1976, p. 13). 
A concepção de pesquisa aqui compreendida no processo de formação de docentes e no exercício da docência não está orientada pelos pressupostos da epistemologia da prática, os quais se atêm exclusivamente a problemas imediatos da prática, ou seja, aqueles em que as atividades de compreensão da realidade e de produção de conhecimento no exercício da profissão docente se limitam ao fato concreto aparente. Segundo Schön (2000, p. 37), "Na perspectiva da racionalidade técnica [...], um profissional competente está sempre preocupado com problemas instrumentais. Ele busca os meios mais adequados para a conquista de fins fixos".

Ao contrário da racionalidade técnica empreendida por Donald Schön (2000), Minayo (2008, p. 16) afirma que "É a pesquisa que alimenta a atividade de ensino e a atualiza frente à realidade do mundo", principalmente se intencionalmente articulada à perspectiva de superação da dicotomia teoria-prática, com vistas à transformação da realidade - práxis. Nessa mesma compreensão de pesquisa segue Vianna (2007, p. 13), a saber:

A pesquisa busca explicar situações problemáticas que estuda e analisa, apresentando, ao final, inferências e conclusões. [...] Os estudos observacionais, como pode ser instruído das colocações anteriores, levam à observação de campo, técnica fundamental usada na maioria das pesquisas qualitativas, que traduz descrições detalhadas de acontecimentos, pessoas, ações e objetos em um determinado contexto.

Desse modo, a observação constitui uma das atividades de pesquisa importantes no processo de formação docente, para sua apreensão e prática no exercício da docência, se se pretende a realização de processos formativos de perspectiva crítico-emancipadora.

Vale ressaltar que, no tocante ao componente curricular Estágio Supervisionado VI do curso de Pedagogia UNEB/PARFOR/Polo Medeiros Neto, a ementa que orienta o planejamento de ensino inicia-se por exigir a identificação de características socioeconômicas e culturais da escola e dos espaços não escolares. Assim, entende-se que esse requisito, por si só, demanda do docente um trabalho de produção de conhecimento crítico-emancipador, por quatro motivos: (i) ensinar não é transferir conhecimento; (ii) o processo de formação deve considerar o discente como sujeito do próprio processo de formação, e não apenas um receptor, ou seja, deve considerar sua autonomia para que possa pensar e propor sobre o campo de atuação profissional; (iii) docência é lugar de trabalho coletivo, ou seja, trabalho entre 
os sujeitos, e não trabalho para eles; e (iv) em uma sociedade onde a desigualdade, a injustiça social e as contradições do sistema capitalista são evidentes, a luta de classes exige disputa de projetos, sobretudo de um projeto de educação — no caso, o Projeto Histórico da classe trabalhadora. A seguir está reproduzida a referida ementa ${ }^{2}$.

Identifica características sócio-econômicas e culturais da escola e dos espaços nãoescolares, compreendendo a prática educativa vivenciada através da pesquisa-ação. Articula a teoria com a prática num processo integralizador, buscando intervir de forma crítica e transformadora no processo de ensino-aprendizagem na Educação Infantil, nos anos/séries iniciais do Ensino Fundamental, na Educação de Jovens e Adultos e nos espaços não-escolares, criando e recriando elementos de discussão dos componentes curriculares do Curso, numa perspectiva problematizadora. Reflete a sua prática e reformula a sua práxis educativa (UNEB, 2008, p. 43).

Essa indicação da ementa possibilitou problematizar o trabalho como atividade concreta na sociedade capitalista e sua abstração como categoria de análise sobre o que ele tem representado para a classe trabalhadora e para a categoria docente. Quais as condições materiais para realizar o trabalho docente na perspectiva da unidade teoria-prática (práxis)? Como trabalhar em prol da produção da vida, na sociedade capitalista, a partir da compreensão ontológica do trabalho? São questões não exploradas nos limites deste artigo, porque, em certa medida, distanciam-se do objetivo aqui proposto, mas que subsidiam a docência para o processo de formação docente de perspectiva crítico-emancipadora, ao tempo em que materializam uma relação entre ensino, pesquisa e práxis - conhecer pressupõe pesquisar, e vice-versa.

Ora, se "não é a consciência que determina a vida, mas a vida que determina a consciência" (MARX; ENGELS, 2009, p. 32), no caso das relações entre docente e discente isso exige a produção de conhecimento a partir de teorias e práticas revolucionárias que venham a colaborar com a evolução da consciência, em acordo com o Projeto Histórico da classe trabalhadora, daí a assertiva de que a formação docente pressupõe sólida formação teórica.

\footnotetext{
2 Embora a ementa se refira também a pesquisa-ação, optou-se aqui por não fazer a discussão conceitual dessa metodologia de pesquisa e desenvolver a relação entre ensino, pesquisa e extensão a partir da orientação de atividades práticas para o conhecimento da realidade e a realização de atividades teórico-metodológicas para elaboração do projeto de intervenção e do seminário Encontro de Coordenadores, descrito adiante.
} 
A segunda parte da ementa apresenta o seguinte enunciado: "Articula a teoria com a prática num processo integralizador, buscando intervir de forma crítica e transformadora no processo de ensino-aprendizagem" (UNEB, 2008, p. 24). Entende-se, aqui, que a própria ementa, de forma pertinente, aponta a perspectiva de ação e atitude pedagógica que se deve assumir ao orientar os graduandos a inserir-se no campo de atuação profissional. Trata-se de uma perspectiva curricular que, de antemão, alinha-se a uma perspectiva crítico-emancipadora para a formação docente, condizente com o que este estudo defende como perspectiva formativa para a docência.

No entanto, é preciso considerar que não se trata de uma atividade simples. Fazer a articulação entre teoria e prática-práxis demanda trabalho, tempo, estudo, pesquisa, materiais diversos, enfim, requer condições materiais para a realização de atividades teórico-prática-práxis. Por exemplo, até meados do ano de 2008, a carga horária de uma disciplina a ser ministrada implicava tempo igual de planejamento, ou seja, para $12 \mathrm{~h}$ semanais de aula correspondiam mais $12 \mathrm{~h}$ semanais para planejamento do trabalho docente. Atualmente, no âmbito das universidades estaduais da Bahia, para o planejamento de aulas são destinadas $2 \mathrm{~h}$ semanais, que podem ser registradas no Plano Individual de Trabalho.

Por seu turno, os docentes em processo de formação inicial no curso de Pedagogia estão imersos em contexto de desvalorização da profissão docente, precarização do trabalho, ausência de plano de carreira e desvinculados da organização sindical, uma vez que $70 \%$ da turma pertencia à vinculação profissional por contrato temporário e, segundo a própria turma, isso impedia a filiação à Associação dos Professores Licenciados do Brasil (APLB).

Resguardadas as necessárias condições de trabalho, a docência encontra brecha para se efetivar nos moldes como está definida neste estudo, porque

o currículo não representa meramente um conceito, um programa de curso ou especificamente conteúdos e atividades didático-pedagógicas, mas uma prática sociocultural carregada de intencionalidades, ou seja, as relações entre o currículo escrito e o currículo prático, vivido num movimento co-relacional entre docente, discente e a instituição, moldam as formas de ensinar e de aprender; de formar, formar-se, reformar, reformar-se, incrementando o processo formativo de conteúdo e metodologia, objetivos e avaliação numa construção coletiva e social pertinente ou não à perspectiva crítica, criadora para ser professor e exercer a profissão (FERREIRA, 2013, 139). 
Cumpre registrar que foram muitas as reuniões com o coletivo de docentes do componente Estágio Supervisionado entre os anos de 2000 e 2010, promovidas pela Pró-Reitoria de Ensino de Graduação (PROGRAD) da UNEB e subgerências correspondentes, nas quais o referido coletivo foi convidado a discutir concepções de formação docente e construir o projeto curricular dos cursos de Pedagogia. Atribuem-se a essas atividades coletivas de estudo, discussão e proposição formativa a natureza crítica e de horizonte transformador, as quais podem ser observadas no projeto curricular dos cursos de Pedagogia da UNEB, quer seja para os currículos dos cursos regulares (oferta contínua) de Licenciatura Plena em Pedagogia, quer seja para o currículo dos cursos/programas especiais, como Pedagogia Rede UNEB 2000 (1998 - 2008), Pedagogia da Terra (2004 - 2010) em parceria como o Programa Nacional de Educação na Reforma Agrária (PRONERA), e Pedagogia PARFOR (2009 - até o momento).

\title{
Trabalho pedagógico em Estágio: possibilidades de articulação entre ensino, pesquisa e práxis?
}

Dessa maneira, é forçosa a interpretação de que pensar a formação docente requer, de modo contundente, a clareza sobre uma concepção de educação e, por conseguinte, uma perspectiva de formação humana. Isso porque os referenciais teórico-metodológicos de um processo formativo, sobretudo de docentes, orientam a docência e contribuem para a definição de uma intencionalidade político-pedagógica na atuação profissional. Se a formação docente incide sobre a docência, os processos formativos não podem prescindir de uma compreensão demarcada de educação.

\begin{abstract}
A educação, quando apreendida no plano das determinações e relações sociais e, portanto, ela mesma constituída e constituinte destas relações, apresenta-se historicamente como um campo da disputa hegemônica. Esta disputa dá-se na perspectiva de articular as concepções, a organização dos processos e dos conteúdos educativos na escola, mais amplamente, nas diferentes esferas da vida social, aos interesses de classe (FRIGOTTO, 2003, p. 25).
\end{abstract}

Portanto, vale a ressalva de que a formação docente pressupõe a clareza de concepção de educação, orientada pelas questões: Educação para quem? Educação para quê? As respostas a essas questões definem, em larga medida, a intencionalidade do trabalho pedagógico que venha a ser realizado, ao mesmo tempo em que orientam 
a relação dialética entre objetivo/avaliação e entre conteúdo/forma. Nesse proceder, os objetivos elencados para o desenrolar das 75 h do componente em apreço serão analisados a seguir.

O componente curricular foi organizado em três momentos distintos: 1) estudo, reflexões e sistematização de conceitos para subsidiar as atividades de intervenção; 2) elaboração de propostas pedagógicas a partir de estudos realizados e outros referenciais que se fizessem necessários; 3) estudo de síntese sobre a função docente. Tais momentos se apresentam autônomos, mas indissociáveis entre si, pois a distinção de momentos na construção do trabalho pedagógico favorece o aprofundamento teóricoprático sobre o objeto de estudo sem, contudo, configurar dicotomia entre eles. "Ampliar o conhecimento é uma exigência ética, assim como o é respeitar o outro, reconhecendo-o como diferente e igual" (RIOS, 2008, p. 83). Assim, para o primeiro momento foram identificados dois objetivos específicos, a saber:

1) Problematizar o papel da escola na atualidade, visando ao estudo das relações entre Sociedade, Educação e Escola;

2) Discutir os desafios da docência para articular a unidade entre teoria e prática no processo de ensino [...] (UNEB, 2015, p. 1).

Observando-se os dois objetivos construídos, verifica-se que estão relacionados às questões macro de educação e da própria docência. O primeiro objetivo, visando ao estudo das relações entre Sociedade, Educação e Escola apresenta uma ação provocativa das relações entre sociedade, educação e escola, indagando-se a escola sobre o que ela tem feito a respeito dessa relação, assim como tem-se posicionado diante das demandas da sociedade.

Esse primeiro aspecto procura responder ao primeiro enunciado da ementa, citada anteriormente, que orienta o estudo acerca das características socioeconômicas e culturais da escola. Para tanto, buscou-se, a partir do pressuposto teóricometodológico da Educação do Campo, realizar o inventário da escola — atividade de pesquisa que objetiva reunir informação de aspectos materiais ou imateriais de determinada realidade (FREITAS, 2011; CALDART et al., 2016).

O inventário da realidade, quando produzido pelo discente, subsidia a sua aproximação da realidade em que atuará, assim como constitui fonte robusta de informações para análise rigorosa e sistemática dessa realidade, bem como para 
propor intervenções pedagógicas condizentes, próprias, objetivas e demandadas por essa mesma realidade. Mais adiante, são apresentados os projetos de intervenção pedagógicas originados do trabalho teórico-metodológico realizado no componente curricular em questão. Novamente, aqui se reafirma a primeira relação entre ensino, pesquisa e práxis, referida anteriormente — apropriação de conhecimento — porque o ato de conhecer, no âmbito da formação, pressupõe ensino e pesquisa.

Ainda no que se refere ao segundo objetivo, planejou-se discutir os desafios da docência para articular a unidade entre teoria e prática no processo de ensino da educação básica. Tratou-se, inicialmente, de compreender o conceito de práxis. No desenvolvimento dos trabalhos, havia a preocupação de que a práxis pedagógica não fosse abordada no componente tão somente como um conceito, mas também como um exercício inerente ao processo formativo dos sujeitos. Com isso, foi estudado o conceito de práxis em Vázquez (2011, p. 240), a saber:

Ao afirmar-se anteriormente que a atividade teórica por si só não é práxis, afirma-se, também, que enquanto a teoria permanece em seu estado puramente teórico não se transita dela à práxis e, portanto, esta é de certa forma negada. Temos, assim, uma contraposição entre teoria e prática que tem sua raiz no fato de que a primeira, em si, não é prática, isto é, não se realiza, não se plasma, não produz nenhuma mudança real. Para produzi-la, não basta desenvolver uma atividade teórica. É preciso atuar praticamente, ou seja, não se trata de pensar um fato e sim de revolucioná-lo; os produtos da consciência têm de se materializar para que a transformação ideal penetre no próprio fato. [...].

Assim, a docente propôs, aos estudantes, atividades em que eles expusessem suas experiências de intervenção pedagógica em períodos anteriores de estágio curricular supervisionado, avaliassem essas experiências e apresentassem alternativas para novas práticas a serem desenvolvidas no componente Estágio Supervisionado VI. Isto é, a partir de estudos já realizados e de experiências com o exercício da profissão, deveriam buscar saber qual aspecto teórico-metodológico poderiam aprofundar nos estudos desse componente curricular.

Com esse mesmo propósito, a maioria das indagações e dúvidas dos estudantes eram respondidas com outras indagações e indicações de leituras que promovessem reflexões e aprofundamentos sobre o tema em questão, de modo que os estudos realizados se materializassem em proposições práticas nos projetos de intervenção, 
construindo-se, assim, uma outra relação entre ensino, pesquisa e práxis auto-organização dos estudantes/respeito aos educandos.

A partir desse trabalho foram elaborados vinte projetos de intervenção pedagógica: treze na área de coordenação pedagógica, quatro realizados em sala de aula na Educação Infantil e três realizados em salas de aula das séries iniciais do Ensino Fundamental. O Quadro 1, a seguir, mostra esses projetos.

Quadro 1 - Projetos e Temas de Intervenção Pedagógica de Professores-Estudantes ${ }^{3}$

\begin{tabular}{|l|l|}
\hline Área de Intervenção & Temas de abrangência \\
\hline Pedagógica & $\begin{array}{l}\text { Oficina da criatividade: o jogo, o brinquedo e a brincadeira } \\
\text { como ferramentas para a aprendizagem. } \\
\text { O papel do educador e seu compromisso com a formação do } \\
\text { educando no espaço escolar. } \\
\text { A atuação do coordenador pedagógico. } \\
\text { A avaliação como mecanismo do trabalho docente. } \\
\text { Indisciplina na sala de aula. } \\
\text { Acompanhamento do trabalho pedagógico na Educação Infantil. } \\
\text { Direitos Humanos - sexualidade. } \\
\text { A arte de contar histórias - ludicidade e Educação infantil. } \\
\text { A música como instrumento facilitador da leitura e escrita na } \\
\text { Educação Infantil. } \\
\text { Leitura e Escrita, descoberta de um novo mundo. } \\
\text { Ética e cidadania. } \\
\text { Lendo e escrevendo - aprendendo um mundo de } \\
\text { possibilidades. }\end{array}$ \\
\hline $\begin{array}{l}\text { Sala de aula } \\
\text { (Educação Infantil) }\end{array}$ & $\begin{array}{l}\text { Música e movimento. } \\
\text { A arte de contar histórias. } \\
\text { Cantando e aprendendo. } \\
\text { Leitura e escrita. }\end{array}$ \\
\hline $\begin{array}{l}\text { Sala de aula (séries } \\
\text { iniciais do Ensino }\end{array}$ & $\begin{array}{l}\text { Alimentação saudável. } \\
\text { Brincando também se aprende a ler e escrever. } \\
\text { Alimentação saudável. }\end{array}$ \\
\hline
\end{tabular}

Fonte: Relatório de Estágio Curricular Supervisionado (UNEB, 2015).

Os projetos apresentaram-se contextualizados e coerentes com os processos de formação que a turma vinha vivenciando no histórico da sua formação ao longo do curso de Pedagogia.

\footnotetext{
${ }^{3}$ Termo utilizado no Programa de Formação para identificar os discentes.
} 
À medida que os projetos eram esboçados, buscava-se criar a novidade, em relação a uma prática de perspectiva de transformação, provocando-se a problematização das dificuldades, dos desafios e dos diálogos críticos que se estabeleciam com as teorias estudadas. Também a partir dessa elaboração, seguiamse as orientações, os estudos e as proposições para o movimento dos pares dialéticos, referenciados por Freitas (2008): objetivos/avaliação, conteúdo/forma, sintetizandose as abordagens temáticas estudadas e visando-se, sobretudo, à formulação de reflexões acerca do Projeto Político Pedagógico da escola, ao planejamento, às relações entre docentes e discentes, à avaliação e às funções do coordenador pedagógico da escola.

Todas as atividades foram orientadas considerando-se que a Organização do Trabalho Pedagógico requer condições materiais para que se proceda em atenção a alguns princípios fundamentais no seu desdobramento: diálogo entre os sujeitos da escola; reflexividade crítica acerca do processo de ensino e de aprendizagem; estudo continuado sobre a própria organização do trabalho pedagógico da escola, articulação com a comunidade onde está inserida e com a realidade sociocultural dos estudantes, entre outras (FREITAS, 2008; FERREIRA, 2015).

O terceiro momento do componente buscou perseguir o terceiro objetivo elencado no coletivo da turma (docente e discentes): "refletir sobre a função docente, sua natureza e relações com a construção do conhecimento profissional" (UNEB, 2015, p. 1). Partiu-se do entendimento de que, na investigação, a docência deve iniciarse pela realidade concreta aparente e a ela retornar como concreto pensado. Ora, se o trabalho é iniciado problematizando-se as relações entre sociedade, educação e escola, com base na definição da intencionalidade da docência e do trabalho pedagógico como todo, então a sua conclusão pressupõe o retorno às questões iniciais, de modo a se proceder a outros estudos, outras reflexões; uma avaliação para outras proposições práticas no exercício continuado da docência. Fizeram-se pertinentes, portanto, as clássicas perguntas de orientação da docência: ensinar o quê? A quem? Para quê? E como avaliar?

Para esse momento, o grupo decidiu tomar para si a indagação posta por Rios (2008, p. 86): “Que lugar tem a liberdade e autonomia do trabalho docente?”. Ainda, a ação do grupo tomou como fundamento a seguinte reflexão: 
Não somos livres isoladamente. A liberdade e autonomia de professores e alunos é construída na relação, na reciprocidade. E articulam-se sempre com a responsabilidade. Os princípios éticos, mais uma vez, são a referência para essa construção. (RIOS, 2008, p. 87).

Nesse proceder, a liberdade e a autonomia construídas pela reciprocidade entre docente e discentes pode ampliar em larga medida o horizonte formativo dos sujeitos, pois possibilita tomadas de decisão coletivas que definirão os pares dialéticos objetivo/avaliação, conteúdo/forma. Daí se infere que a relação ensino, pesquisa e práxis pressupõe, também, liberdade e autonomia dos sujeitos (docente e discentes) em processos de formação.

\section{À guisa de conclusão}

Constatou-se que ensino, pesquisa e práxis são instâncias formativas autônomas, mas indissociáveis entre si. No âmbito do curso de Pedagogia/PARFOR, nos componentes curriculares Fundamentos da Práxis Pedagógica VI e Estágio Supervisionado VI, estabeleceram-se relações de produção de conhecimento, trabalho coletivo, auto-organização dos estudantes, respeito aos educandos e liberdade e autonomia de docentes e discentes.

Essas relações, na medida em que constituem eixo estruturante da docência, subsidiam qualitativamente os propósitos e a natureza dos processos de formação docente construídos na mediação entre docente e discentes.

Nesse sentido, as relações estabelecidas contribuem com uma perspectiva crítico-emancipadora dos processos de formação docente, pois estão respaldadas em processos educativos que envolvem: a problematização da realidade social em que estão inseridos docente e discentes; a busca de aprofundamento teórico-metodológico e diálogo entre os sujeitos da escola; reflexividade crítica acerca do processo de ensino e de aprendizagem; tomada de decisão coletiva sobre a organização do trabalho pedagógico; articulação com a comunidade onde está inserida e com a realidade sociocultural dos estudantes.

Cabe à docência enfrentar, lutar, resistir coletivamente junto aos pares e a outras instâncias de ensino e da organização sindical, em nível local, nacional e 
internacional, buscando fortalecimento e engajamento político em prol da ampliação da profissionalidade docente e do reconhecimento e da valorização do magistério como profissão, de modo a ampliar as condições de realizar ensino articulado à pesquisa e à práxis.

Em síntese, se se considerar a telha de vidro no poema de Rachel de Queiroz (QUEIROZ, 2016) como a disposição para olhar mais criticamente as proposições formativas para a docência e para o próprio trabalho que realiza ao ensinar, então as possibilidades de realização de um trabalho cada vez mais crítico e de perspectiva emancipadora talvez possam ser vistas no horizonte.

Por fim, a relação entre ensino, pesquisa e práxis mostra-se como a possibilidade de um trabalho significativo na formação docente, porque pressupõe possibilidades concretas de relações que venham a transcender relações verticalizadas e/ou autoritárias entre docentes e discentes, atentando, sobretudo, para a construção de processos de sólida formação teórica e construção de valores humanos, políticos, culturais, estéticos e éticos.

\section{Referências}

ANTUNES, R. Os sentidos do trabalbo: ensaio sobre a afirmação e a negação do trabalho. 2. ed. São Paulo: Boitempo, 2009.

BRASIL. Ministério da Educação. Lei no 9.394, de 20 de dezembro de 1996. Estabelece as Diretrizes e Bases da Educação Nacional. Diário Oficial da União, Brasília, DF, 23 dez. 1996. Disponível em: http://www.planalto.gov.br/ccivil_03/leis/19394.htm. Acesso em: 06 maio 2020.

BRASIL. Ministério da Educação. Resolução n 2 do Conselho Nacional de Educação, de 19 de fevereiro de 2002. Institui a duração e a carga horária dos cursos de licenciatura, de graduação plena, de formação de professores da Educação Básica em nível superior. Diário Oficial da União, Brasília, DF, 04 mar. 2002. Seção 1, p. 9. Disponível em: http://portal.mec.gov.br/cne/arquivos/pdf/CP022002.pdf. Acesso em: 06 maio 2020.

BRASIL. Ministério da Educação. Resolução n ${ }^{\circ} 1$ do Conselho Nacional de Educação, de 15 de maio de 2006. Institui Diretrizes Curriculares Nacionais para o Curso de Graduação em Pedagogia, licenciatura. Diário Oficial da União, Brasília, DF, 16 maio 2006, Seção 1, p. 11. Disponível em: http://portal.mec.gov.br/cne/arquivos/pdf/rcp01_06.pdf. Acesso em: 22 abr. 2020.

CALDART, R. S. Educação do Campo. In: CALDART, R. S. et al. (Orgs.). Dicionário da Educação do Campo. São Paulo: Expressão Popular, 2012a. p. 257-264. 
CALDART, R. S. Caminhos para a transformação da escola. In: AUED, B. W.; VENDRAMINI, C. R (Orgs.). Temas e problemas no ensino em escolas do campo. São Paulo: Outras Expressões, 2012b. p. 26-58.

CALDART, R. S. et al. Inventário da Realidade: guia metodológico para uso nas escolas do campo. Guia discutido no Seminário Educação em Agroecologia nas Escolas do Campo. Veranópolis, RS: IEJC, 2016.

FERREIRA, M. J. L. Formação de professores numa perspectiva crítica e criadora ou quando a leitura reinventa a ação docente. In: SOARES, S. R.; SOARES, I. M. F.; BARREIRO, M. (Orgs.). Série Práxis e Docência Universitária: ensino para a autonomia inovando a formação profissional. Salvador: EDUNEB, 2013. p. 131-162.

FERREIRA, M. J. L. Docência na Escola do Campo e Formação de Educadores: qual o lugar do trabalho coletivo? Orientadora: MOLINA, M. C. 2015, 235 p. Tese (Doutorado em Educação) Programa de Pós-Graduação em Educação, Faculdade de Educação, Universidade de Brasília, Distrito Federal, 2015.

FERREIRA, M. J. L.; MOLINA, M. C. Formação de educadores do campo e trabalho coletivo: refletindo sobre experiências da UNB e da formação docente em Cuba. Revista Congreso Universidad, Havana, v. 5, n. 4, p. 110-124, ago. 2016. Disponível em: http://revista.congresouniversidad.cu/index.php/rcu/article/view/762/724. Acesso em: 08 maio 2020.

FREIRE, P. Pedagogia da autonomia: saberes necessários à prática docente. 31. ed. São Paulo: Paz e Terra, 2005.

FREITAS, L. C. de. Projeto histórico: ciência pedagógica e "didática". Educaşão \& Sociedade, Campinas, n. 27, p. 122-140, 1987.

FREITAS, L. C. de. Crítica da organização do trabalho pedagógico e da didática. 9. ed. São Paulo: Papirus, 2008.

FREITAS, L. C. de. A escola única do trabalho: explorando os caminhos de sua construção. In: CALDART, R. S. Caminhos para a Transformação da Escola: reflexões desde práticas da licenciatura em educação do campo. São Paulo: Expressão Popular, 2011. p. 156-174.

FRIGOTTO, G. Educaşão e a crise do capitalismo real. 5. ed. São Paulo: Cortez. 2003.

KOSIK, K. Dialética do Concreto. São Paulo: Paz e Terra, 1976.

MARX. K.; ENGELS, F. A ideologia alemã. São Paulo: Expressão Popular, 2009.

MINAYO, M. C. de S. O desafio da pesquisa social. In: MINAYO, M. C. de S. (Org.). Pesquisa Social: teoria, método e criatividade. Petrópolis, RJ: Vozes, 2008. p. 9-29.

MOLINA, M. C. Reflexões sobre o significado do protagonismo dos movimentos sociais na construção de políticas públicas de Educação do Campo. In: MOLINA, M. C. (Org.). Educação do Campo e Pesquisa II. Brasília: MDA/MEC, 2010. p. 137-149.

PIMENTA, S. G.; LIMA, M. S. L. Estágio e docência. São Paulo: Cortez, 2004. 
QUEIROZ, R. de. Telha de Vidro. In: QUEIROZ, R. de. Serenata: poesias. 2. reimp. Fortaleza: Armazém da Cultura, 2016.

RIOS, T. A. A dimensão ética da aula: ou o que nós fazemos com eles? In: VEIGA, I. P. A. (Org.). Aula: gênese, dimensões, princípios e prática. Campinas: Papirus, 2008. p. 73-93.

RIOS, T. A. Compreender e ensinar: por uma docência da melhor qualidade. 8. ed. São Paulo: Cortez, 2010.

ROLDÃO, M. do C. Função docente: natureza e construção do conhecimento profissional. Revista Brasileira de Educação, v. 12, n. 34, jan./abr. 2007.

SCHÖN, D. A. Educando o profissional reflexivo: um novo design para o ensino e a aprendizagem. Trad. Roberto Cataldo Costa. Porto Alegre: Artmed, 2000.

SILVA, K. A. C. P. C. da. A formação de professores na perspectiva crítico-emancipadora. Linhas Críticas, Brasília-DF. v. 17, n. 32, p. 13-31, jan/abr. 2011.

SILVA, K. A. C. P. C. da. Professores, formação stricto sensu e o desenvolvimento da pesquisa. Orientadora: BARBOSA, I. G. 2008, 292 p. Tese (Doutorado em Educação) - Programa de Pós-graduação em Educação, Faculdade de Educação, Universidade Federal de Goiás, Goiânia, 2008.

TAFFAREL, C. Z. Pedagogia Histórico-crítica e Metodologia de Ensino Crítico-superadora da educação física: nexos e determinações. Revista Nuances: Estudos sobre Educação, Presidente Prudente, v. 27, n. 1, p. 5-23, jan./abr. 2016. http://dx.doi.org/10.14572/nuances.v27i1.3962.

TRIVIÑOS, A. N. S. Introdução à pesquisa em ciências sociais: a pesquisa qualitativa em educação - o positivismo, a fenomenologia, o marxismo. São Paulo: Atlas, 1987.

UNIVERSIDADE DO ESTADO DA BAHIA (UNEB). Departamento de Educação, Campus X. Projeto Político Pedagógico do Curso de Pedagogia/PARFOR. Secretaria Acadêmica do Curso, 2008.

UNIVERSIDADE DO ESTADO DA BAHIA (UNEB). Departamento de Educação, Campus X. Relatório de Fundamentos da Práxis Pedagógica VI e Estágio Supervisionado VI. Secretaria do Curso de Licenciatura em Pedagogia/PARFOR, 2015.

VÁZQUEZ, A. S. Filosofia da Práxis. Trad. Maria Encarnacion Moya. São Paulo: Expressão Popular, 2011.

VEIGA, I. P. A.; ARAÚJO, J. C.; KAPUZINIAK, C. Docência: uma construção éticoprofissional. Campinas: Papirus, 2005.

VIANNA, H. M. Pesquisa em Educação: a observação. Brasília: Plano Editora, 2007.

RECEBIDO: $19 / 05 / 2020$

APROVADO: 06/10/2020
RECEIVED: 05/19/2020

APPROVED: $10 / 06 / 2020$
RECIBIDO: 19/05/2020

APROBADO: $16 / 10 / 2020$ 